\title{
Cardioprotection by ICRF187 against high dose anthracycline toxicity in children with malignant disease
} Frances A Bu'Lock, Henrique M Gabriel, Anthony Oakhill, Martin G Mott,
Robin P Martin

\begin{abstract}
Objective-A pilot study to assess the efficacy of ICRF187 as a protective agent against the cardiotoxic effects of anthracycline drugs used to treat childhood malignancies.
\end{abstract}

Design-A study of cardiac function in children treated receiving ICRF187 ((s)-(+)-1,2 bis (3,5-dioxopiperazenyl) propane) in addition to anthracycline therapy compared with contemporary controls selected retrospectively on the basis of anthracycline dose matching.

Patients-Five children in whom recurrence of malignant disease was re-treated with chemotherapy containing anthracycline drugs and additional ICRF187 (supplied on a compassionate-use basis) (cumulative anthracycline doses 550-1650 $\mathrm{mg} / \mathrm{m}^{2}$ ). Five more children with recurrence of malignant disease were re-treated to similar cumulative anthracycline doses (600-1150 $\left.\mathrm{mg} / \mathrm{m}^{2}\right)$ without ICRF187.

Methods-Cardiac function was assessed clinically and echocardiographically throughout treatment. Clinical and echocardiographic state were compared before treatment and after completion of therapy within and between groups treated with and without ICRF187.

Results-Two patients treated without ICRF187 developed symptomatic congestive cardiac failure from which one died. Another developed considerable but as yet asymptomatic left ventricular dysfunction. No patient receiving additional ICRF187 developed cardiac failure or left ventricular dysfunction. There were no significant differences in cumulative anthracycline dose, dose increase, type of anthracycline used, survival rate, or length of survival between groups. Left ventricular shortening fraction fell by a mean of $1.0 \%$ in patients receiving ICRF187 and by a mean of $11 \%$ in the patients treated without it $(p=0.04)$. Conclusions-ICRF187 seems to have provided highly effective cardioprotection to this small group of children with end-stage malignancy. Severe cardiotoxicity was seen in a similar group treated with comparable anthracycline doses but without ICRF187.

\section{(Br Heart F 1993;70:185-188)}

The cardiotoxicity of anthracycline compounds such as daunorubicin, doxorubicin, and epirubicin continues to be a major source of concern to those who treat childhood malignancy. The irreversible loss of cardiac myocytes which occurs with increasing cumulative dose eventually leads to functional impairment, congestive cardiac failure and death in a considerable proportion of those treated (3-18\% at anthracycline doses of $\left.<700 \mathrm{mg} / \mathrm{m}^{2}\right)^{1}$ Cardiotoxicity may occur during or shortly after treatment or may only manifest itself many years later in an otherwise healthy survivor. ${ }^{2}$ However, the widespread use of anthracyclines is one of the principal reasons why more than two thirds of children with cancer are now achieving longterm remission and cure of their malignancies. Thus both the short and longer term cardiotoxic effects of such drugs are of considerable importance.

It seems that the antitumour efficacy and cardiotoxicity of these drugs are mediated through different mechanisms. ${ }^{34}$ Several approaches to ameliorate the cardiotoxicity of anthracyclines without reducing their therapeutic efficacy have been studied. These have included the use of prolonged or continuous anthracycline infusions, ${ }^{56}$ vitamin $\mathrm{E}^{3}$ and $\mathrm{N}$-acetylcysteine, ${ }^{7}$ but none of these has had a major impact on clinical practice. The bispiperazinedione compound, ICRF187, ((s)-(+)-1,2-bis (3,5-dioxopiperazenyl) propane) has been shown to offer considerable protection from anthracycline cardiotoxicity both in animal studies ${ }^{89}$ and in adult patients with breast cancer. ${ }^{1011}$ There are, however, no data on its use in children. We have treated five children with advanced malignant disease, who were receiving chemotherapy with high cumulative anthracycline doses together with ICRF187 on a compassionate-use basis. Their clinical and echocardiographic (echo) data are compared with those from five similar children treated concurrently for whom supplies of ICRF187 were unavailable.

\section{Patients and methods}

\section{PATIENT GROUP AND ANTHRACYCLINE}

DOSAGE

All 10 patients (table 1) had recurrence of malignant disease with or without metastatic spread and in only three patients $(4,6$, and 10) was there believed to be any likelihood of achieving long-term remission or cure. In the remainder, chemotherapy was prescribed to reduce symptoms, and/or prolong a reasonable quality of life. A limited supply of ICRF187 was made available to us on a com-
B16 8ET.

Accepted for publication 18 January 1993 
Table 1 Treatment data and cardiac outcome*

\begin{tabular}{|c|c|c|c|c|c|c|c|}
\hline No & Diagnosis & $\begin{array}{l}\text { Age } \\
(y r)\end{array}$ & $\begin{array}{l}\text { First } \\
\text { anthracycline }\end{array}$ & $\begin{array}{l}\text { Cumulative } \\
\text { dose } \\
\left(m g / m^{2}\right)\end{array}$ & $\begin{array}{l}\text { New } \\
\text { anthracycline }\end{array}$ & $\begin{array}{l}\text { Cumulative } \\
\text { dose } \\
\left(\mathrm{mg} / \mathrm{m}^{2}\right)\end{array}$ & $\begin{array}{l}\text { Cardiac } \\
\text { dysfunction? }\end{array}$ \\
\hline \multicolumn{8}{|c|}{ Patients also treated with Treatment ICRF187 } \\
\hline $\begin{array}{l}1 \\
2\end{array}$ & $\begin{array}{l}\text { Osteosarcoma } \\
\text { Osteosarcoma }\end{array}$ & $\begin{array}{l}17 \cdot 5 \\
10 \cdot 4\end{array}$ & $\begin{array}{l}\text { Doxo } \\
\text { Epi }\end{array}$ & & $\begin{array}{l}\text { Epi } \\
\text { Epi }\end{array}$ & $\begin{array}{r}850 \\
1650\end{array}$ & $\begin{array}{l}\text { No } \\
\text { No }\end{array}$ \\
\hline 3 & $\begin{array}{l}\text { Bone metastasising } \\
\text { renal tumour }\end{array}$ & $\begin{array}{r}10 \cdot 4 \\
5 \cdot 0\end{array}$ & Epi & 455 & $\begin{array}{l}\text { Ep1 } \\
\text { Epi }\end{array}$ & 821 & No \\
\hline 4 & AML relapse & $17 \cdot 5$ & Dauno & 400 & $\begin{array}{l}\text { Dauno } \\
+ \text { BMT }\end{array}$ & $\begin{array}{l}550 \\
+ \text { BMT }\end{array}$ & No \\
\hline \multicolumn{2}{|c|}{$\begin{array}{l}5 \quad \text { Neuroblastoma(B4) } \\
\text { Mean (SD) }\end{array}$} & $\begin{array}{l}3.9 \\
10.9(6.5)\end{array}$ & Epi & $\begin{array}{l}438 \\
439(22)\end{array}$ & Epi & $\begin{array}{l}756 \\
925(421)\end{array}$ & No \\
\hline \multicolumn{8}{|c|}{ Patients not treated with ICRF187 } \\
\hline 6 & Rhabdomyosarcoma(B4) & $10 \cdot 5$ & Epi & 300 & Epi & 1000 & CCF \\
\hline 7 & Neuroblastoma(B4) & $8 \cdot 4$ & Epi & 600 & Epi & 1150 & $\downarrow S F$ \\
\hline 8 & Neuroblastoma(B4) & $7 \cdot 2$ & Epi & 500 & Epi & 700 & No \\
\hline 9 & AML relapse & $6 \cdot 8$ & $\begin{array}{l}\text { Dauno } \\
\text { + Doxo }\end{array}$ & 405 & Dauno & 705 & CCF \\
\hline $\begin{array}{l}10 \\
\text { Mea }\end{array}$ & $\begin{array}{l}\text { Hodgkin's relapse(4B) } \\
\text { (SD) }\end{array}$ & $\begin{array}{l}16.5 \\
9.9(4 \cdot 0)\end{array}$ & Epi & $\begin{array}{l}450 \\
445(114)\end{array}$ & Doxo & $\begin{array}{l}600 \\
836(232)\end{array}$ & No \\
\hline
\end{tabular}

*All patients had recurrent disease with or without metastases. AML, acute myeloid leukaemia; BMT, bone marrow transplantation; Epi, epirubicin; doxo, doxorubicin; dauno; daunorubicin; CCF, congestive cardiac failure; $\downarrow$ SF, reduced shortening fraction.

passionate-use basis with which we were able to treat five patients. Over the same period several other children received similar treatments for end-stage disease and for whom supplies of ICRF187 could either not be obtained or not be administered. The five patients treated without ICRF187 whose anthracycline doses most closely matched those receiving it (from dose when ICRF187 was started to end of treatment) were identified from our database. Thus though this is not a randomised control group, it is a group of concurrently treated controls selected retro-spectively for close dose-matching. Because all patients treated with anthracycline drugs undergo regular detailed echocardiographic examinations we were able to compare clinical and cardiac functional outcome in those who also received ICRF187 and the controls.

Four of the five patients receiving ICRF 187 (aged $3.9-17.5$ (mean 10.9 years) had solid tumours and one had had multiple relapses of acute myeloid leukaemia (AML). Three had received epirubicin at first treatment, one had received doxorubicin, and one had received daunorubicin, to a mean cumulative anthracycline dose of $439 \mathrm{mg} / \mathrm{m}^{2}$ (range 400-455 mg/m $\mathrm{m}^{2}$ ). Four then received epirubicin with ICRF187 and one received daunorubicin with ICRF187 to a mean total cumulative dose of $925 \mathrm{mg} / \mathrm{m}^{2}$ (550-1650 $\mathrm{mg} / \mathrm{m}^{2}$ ). Patient 4 also underwent bone marrow transplantation after conditioning therapy with $120 \mathrm{mg} / \mathrm{kg}$ of cyclophosphamide and $1440 \mathrm{cGy}$ of total body irradiation.

The five contemporary controls were aged 6.8-16.5 years (mean 9.9). Four had recurrent solid tumours and one had recurrence of AML. Four had previously received epirubicin and one had received doxorubicin and daunorubicin, to a mean cumulative anthracycline dose of $441 \mathrm{mg} / \mathrm{m}^{2}\left(300-600 \mathrm{mg} / \mathrm{m}^{2}\right)$. Further treatment was with epirubicin in three and with doxorubicin and daunorubicin in one each, to a mean total cumulative dose of $831 \mathrm{mg} / \mathrm{m}^{2}(600-1150)$.

In all cases where it was used, ICRF187 was administered 30 minutes before the anthracyline (dose ratio 10 to 1 ).

\section{CARDIOLOGICAL ASSESSMENT}

A cardiologist examined each patient before each dose of anthracycline was given and about a month after the last treatment. Symptoms potentially attributable to cardiac dysfunction, such as dyspnoea, reduced exercise tolerance, or oedema, were noted and a full cardiovascular examination was performed. The patient was placed in the semirecumbent, left lateral position and a detailed echocardiographic examination was performed from the standard views. This was recorded onto videotape by means of a Hewlett Packard 77020AC ultrasound scanner. All videotapes were analysed by one observer using the Hewlett Packard on-line analysis package.

Cross sectional echocardiography was used for qualitative assessment of overall anatomy and uniformity of function. The presence of any wall dyskinesia was also noted. The $M$ mode echocardiogram was recorded from the cross sectional parasternal long-axis view with the cursor positioned so as to section the left ventricle (LV) just distal to the tips of the mitral valve leaflets. The paper speed was 100 $\mathrm{cm} / \mathrm{s}$ and a simultaneous electrocardiogram was also recorded.

Diastolic LV cavity (LVDD) and posterior wall (LVPWD) dimensions were measured at the point of maximum posterior excursion of the posterior wall. Systolic cavity (LVDS) and posterior wall (LVPWS) dimensions were measured at the point of maximum anterior excursion of the posterior wall. Measurements were taken as the mean from a minimum of four cardiac cycles for each scan.

The left ventricular shortening fraction (SF (\%)) was calculated according to the formula

$$
S F=((L V D D-L V D S) / L V D D) \times 100
$$

The left ventricular ejection fraction (EF (\%)) was calculated by the cubed method;

$\mathrm{EF}=\left(\left(\mathrm{LVDD}^{3}-\mathrm{LVDS}^{3}\right) / \mathrm{LVDD}^{3}\right) \times 100$ 
STATISTICAL ANALYSIS

We used the Statistical Package for the Social Sciences (SPSS-PC) to analyse data from the first and last examinations for each patient. Student's $t$ test (unpaired and paired) was used for comparisons.

\section{Results}

There were no significant differences between the group receiving ICRF187 and controls in the types of anthracycline drug given before or after treatment, cumulative anthracycline doses, overall dose increases, or survival. All patients were regularly followed up. Mean (range) time to death or latest follow up was $11(2-15)$ months for controls and 9.8 (3-17) months for those receiving ICRF187 ( $p=0.75$, Student's t test).

\section{OUTCOME}

Two controls (patients 6 and 9) developed congestive cardiac failure, with severe dyspnoea associated with pulmonary and peripheral oedema (table 1). There were other signs of cardiac dysfunction: tachycardia, gallop rhythm, raised jugular venous pressure, and hepatomegaly. In patient 9 symptoms developed less than a month after the last anthracycline treatment. In patient 6 symptoms developed three months later, though echocardiography had shown significant cardiac dysfunction at the "end of treatment" examination. Both were treated with bed rest, fluid restriction, digoxin, and frusemide. Patient 6 had a good short-term response to this treatment, with an improvement in both clinical and echocardiographic state, but later the malignancy progressed and further treatment was deemed inappropriate. Patient 9 deteriorated despite treatment with digoxin and diuretics. She developed a low cardiac output state that was unresponsive to inotropic support and she died soon afterwards. One more child died from recurrent disease. Important (asymptomatic) left ventricular dysfunction developed in one of the other survivors.

No patient treated with ICRF187 developed CCF or later left ventricular dysfunction, though four have now died from recurrent malignant disease.

ECHOCARDIOGRAPHIC RESULTS

There were no significant differences in echocardiographic findings between the two groups before treatment (table 2). Shortening fraction and ejection fraction fell in all controls with treatment (figure). The mean (range) absolute fall in shortening fraction was $10 \cdot 6(2-17) \%$ and in ejection fraction it was $14(1-23) \%$. These variables fell in only three patients treated with ICRF187 and there was no overall change in group values (mean absolute change in shortening fraction $-1.0(-5$ to +4$) \%$ and in ejection fraction $-0.8(-7$ to +5$) \%$. The difference in change in shortening fraction and ejection fraction between groups after treatment was statistically significant $(\mathrm{p}=0.04$ (Student's $t$ test)), but the difference in change in systolic posterior wall thickness was not. Figure 1 shows the pre and post treatment shortening fraction for each control patient plotted alongside the same measurements for those who also were treated with ICRF187. Paired $t$ testing of differences for each patient confirms the disparity in group changes, with $p=0.03$ for controls compared before and after treatment and $p=0.60$ for those given ICRF187. The reduction in contractility in those patients not receiving ICRF187 was accompanied by left ventricular dilatation, from mean LVDD (range) 3.96 (3.68-4.71) $\mathrm{cm}$ before treatment to $4.26(3.88-4.69) \mathrm{cm}$ after treatment $(\mathrm{p}=0.06$ paired $t$ test). There was no change in LVDD in those treated with ICRF187. The fall in shortening fraction was correlated strongly with increasing dose in the controls (Pearson correlation coefficient $(R)$ $=-0.86(p=0.06)$. This relation was abolished by ICRF187 ( $R=-0.08(p=0.97)$.

Long term follow up is limited by the poor outcome in this group of patients, however, one of the surviving control patients has shown a continuing deterioration in cardiac function at 1 year follow up (shortening fraction $=19 \%$ ). The control patient with progressive disease currently has adequately controlled heart failure.

\section{Discussion}

This small group of children with end-stage malignancies received much higher doses of anthracycline drugs than are generally used to treat children with cancer. The cumulative cardiotoxicity with increasing total anthracycline dose means that while the incidence of early symptomatic cardiotoxicity ${ }^{1}$ is around $3 \%$ for cumulative doses of less than 400 $\mathrm{mg} / \mathrm{m}^{2}$, it rises steeply to $18 \%$ at $700 \mathrm{mg} / \mathrm{m}^{2}$. Children are known to be more susceptible

Table 2 Echocardiographic data comparisons (mean (SD))

\begin{tabular}{|c|c|c|c|c|c|c|c|}
\hline \multirow[b]{2}{*}{ Variable } & \multicolumn{2}{|l|}{ Before treatment } & \multicolumn{2}{|l|}{ After treatment } & \multicolumn{3}{|l|}{ Change } \\
\hline & ICRF187 & No ICRF187 & ICRF187 & No ICRF187 & ICRF187 & No ICRF187 & $p$ \\
\hline $\begin{array}{l}\text { Dose }\left(\mathrm{mg} / \mathrm{m}^{2}\right)^{\star} \\
\text { LVDD }(\mathrm{cm}) \\
\text { LVDS }(\mathrm{cm}) \\
\text { LVPWS }(\mathrm{cm}) \\
\text { SF(\%) } \\
\text { EF(\%) }\end{array}$ & $\begin{array}{c}439(22) \\
3.96(0.82) \\
2.74(0.64) \\
1.06(0.28) \\
32.6(3.8) \\
68.4(5.2)\end{array}$ & $\begin{array}{c}441(114) \\
3.96(0.43) \\
2.48(0.41) \\
1.08(0.07) \\
37.6(5.9) \\
75.0(6.9)\end{array}$ & $\begin{array}{c}925(422) \\
3.92(0.89) \\
2.74(0.72) \\
0.92(0.21) \\
31.6(3.6) \\
67.6(5.1)\end{array}$ & $\begin{array}{c}831(233) \\
4 \cdot 29(0 \cdot 3) \\
3 \cdot 13(0 \cdot 27) \\
1.02(0.17) \\
27.0(4 \cdot 9) \\
61(8 \cdot 6)\end{array}$ & $\begin{array}{c}486(411) \\
-0.03(0.41) \\
0.00(0.16) \\
-0.15(0.08) \\
-1.0(3.9) \\
-0.8(5.2)\end{array}$ & $\begin{array}{c}390(224) \\
0.33(0.3) \\
0.64(0.51) \\
-0.07(0.2) \\
-10.6(7.5) \\
-14.0(11.0)\end{array}$ & $\begin{array}{l}\text { NS } \\
\text { NS } \\
0.04 \\
\text { NS } \\
0.04 \\
0.04\end{array}$ \\
\hline
\end{tabular}

*Cumulative anthracycline dose. EF, ejection fraction ((LVDD $\left.\left.{ }^{3}-\mathrm{LVDS}^{3}\right) / \mathrm{LVDD}^{3}\right)$ 100(\%). LVDD, left ventricular diastolic diameter; LVDS, left ventricular systolic diameter; LVPWS, systolic LV posterior wall thickness; SF, shortening fraction ((LVDD-LVDS)/LVDD) 100(\%). 


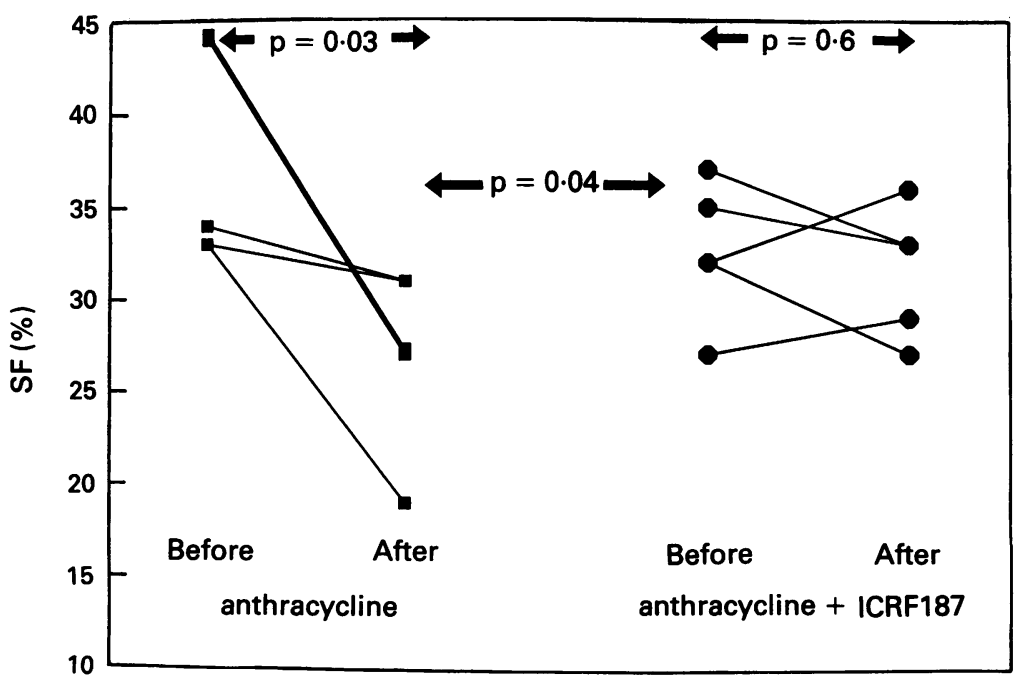

Left ventricular shortening fraction before and after treatment in patients receiving anthracycline therapy compared with the same data in patients receiving similar doses of anthracyclines with additional ICRF187. Statistical comparisons (paired and unpaired $t$ tests) are shown for differences within and between groups.

than adults to anthracycline cardiotoxicity. ${ }^{12}$ The $40 \%$ incidence of symptomatic cardiac failure in children receiving cumulative anthracycline doses between 600 and 1150 $\mathrm{mg} / \mathrm{m}^{2}$ in this study is therefore not surprising. That no child developed cardiac dysfunction when treated with anthracycline doses of between $550 \mathrm{mg} / \mathrm{m}^{2}$ (plus a bone marrow transplant) and $1650 \mathrm{mg} / \mathrm{m}^{2}$ with additional ICRF187 for the latter part of their therapy suggests that ICRF187 provided highly effective cardioprotection. There were no other differences in patient selection, type of anthracycline used, or cumulative anthracycline dose to account for the striking differences seen in both clinical and echocardiographic indices of cardiac outcome. Because there were no significant differences in survival rates or length of survival between groups, it is unlikely that the absence of symptomatic cardiotoxicity in the patients treated with ICRF187 could be explained by chance or by premature death pre-empting the appearance of symptoms. One patient even underwent bone marrow transplantation after retreatment for several recurrences of leukaemia with a total of $550 \mathrm{mg} / \mathrm{m}^{2}$ of daunorubicin, the last $150 \mathrm{mg} / \mathrm{m}^{2}$ of which was administered with ICRF187. Despite pretransplant conditioning including high dose cyclophosphamide and total body irradiation (both of which are known to have additional deleterious effects on cardiac function), cardiac function was within normal limits more than a year later.

More than half of all children treated for malignant disease will receive anthracyclines. Of around 1200 new cases of childhood cancer each year, one third will have acute leukaemia and will receive up to $300 \mathrm{mg} / \mathrm{m}^{2}$ of anthracycline on first treatment. Children with solid tumours may need up to 500 $\mathrm{mg} / \mathrm{m}^{2}$ to give a good chance of cure. Thus perhaps $5 \%$ of the children initially receiving anthracyclines may develop congestive cardiac failure soon after completion of their primary treatment. An additional $30 \%$ or more of survivors are at risk of cardiac decompensation in later life. ${ }^{2}$ This has organisational and resource implications for cardiological services, both for children and for the adults they will become. A significant proportion of children with all types of malignancies will relapse and require further treatment. Because some of these children may still be cured by highly intensive treatment regimens further cardiotoxicity is likely. It will be difficult to achieve a balance between the need to effect a cure and the risks of disease-free survival being compromised by cardiomyopathy. A truly cardioprotective agent would lessen the risk of early anthracycline cardiotoxicity developing in most children with malignant disease and reduce the future population requiring long-term follow up for cardiomyopathy. It might also permit safer use of the intensive salvage regimens needed to cure children with recurrent malignancies.

These preliminary data on the cardioprotectivity of ICRF187 in children are encouraging. Randomised controlled trials in larger numbers of children are clearly both justified and indicated. Such a trial has started in children with recurrent acute lymphoblastic leukaemia.

FAB is supported by a Cancer Research Campaign research training fellowship. MGM is supported by the Cancer and Leukaemia in Childhood trust. ICRF187 was made available by Farmitalia Carlo Erba.

1 Von Hoff DD, Layard MW, Basa P, et al. Risk factors for doxorubicin induced congestive heart failure. Ann doxorubicin induced conges

2 Steinherz LJ, Steinherz PG, Tan CTC, Heller G, Murphy L. Cardiac toxicity 4 to 20 years after completing anthracycline therapy. $\mathscr{F} A M A$ 1991;266:1672-7.

3 Myers CE, McGuire $P$, Liss RH, et al Adriamycin: the role of lipid peroxidation in cardiac toxicity and tumour response. Science 1977;197:165-7.

4 Doroshow JH, Reeves J. Anthracycline enhanced oxygen radical formation in the heart. Proc AACR 1980;21:266.

5 Speyer JL. Green MD, Dubin N, et al. Prospective evaluation of cardiotoxicity during a six hour doxorubicin tion of cardiotoxicity during a sis hour doxorubicin breast. Am $¥$ Med 1985;78:555-63.

6 Garnick M, Weiss AJ, Steele G, et al. Phase 1 trial of long term continuous adriamycin administration. Proc Am Soc Clin Oncol 1981;22:359.

7 Doroshow JH, Lockyer GY, Ifrim I, Myers CE. Prevention of doxorubicin cardiotoxicity in the mouse by N-acetylcysteine $f$ Clin Invest 1981;68:1053-64.

8 Wang G, Finch MD, Trevan D and Hellman $K$. Reduction of daunomycin toxicity by razoxane $B r \dot{f}$ Cancer 1981;43:871-7.

9 Herman EH, Ferrans VJ, Myers CE, Van Vleet JF. Comparison of the effectiveness of ICRF187 and $\mathrm{N}$-acetylcysteine in preventing chronic doxorubicin cardiotoxicity in beagles Cancer Res 1985;45:276-81.

10 Speyer JL, Green MD, Kramer E, et al. Protective effect of the bispiperazinedione ICRF187 against doxorubicininduced cardiac toxicity in women with advanced breast cancer. N Engl $\mathcal{F}$ Med 1988;319:745-52.

11 Speyer JL, Green MD Zeleniuch-Jaquotte A, et al. ICRF permits longer treatment with doxorubicin in women with breast cancer. $f$ Clin Oncol 1992;10:117-27.

12 Pratt CB, Ransom JL, Evans WE. Age-related adriamycin cardiotoxicity in children. Cancer Treat Rep 1978; 63:827-34. 